\title{
BIOLOGIA QUÍMICA: UMA ESTRATÉGIA MODERNA PARA A PESQUISA EM PRODUTOS NATURAIS
}

\author{
Mônica Tallarico Pupo* e Margareth Borges Coutinho Gallo \\ Departamento de Ciências Farmacêuticas, Faculdade de Ciências Farmacêuticas de Ribeirão Preto, Universidade de São Paulo, \\ Av. do Café, s/n, 14040-903 Ribeirão Preto - SP, Brasil \\ Paulo Cezar Vieira \\ Departamento de Química, Universidade Federal de São Carlos, CP 676, 13560-970 São Carlos - SP, Brasil
}

\begin{abstract}
CHEMICAL BIOLOGY: A MODERN STRATEGY FOR THE NATURAL PRODUCTS RESEARCH. This paper presents an overview of the Natural Products Research in Brazil in the last five years (2002-2006), and also discusses how some relevant aspects of the Chemical Biology area could create new research opportunities and challenges for the natural product chemists. In addition, some aspects of the scientific policies and their impact on current projects are discussed.
\end{abstract}

Keywords: chemical biology; natural products; molecular biology.

\section{INTRODUÇÃO}

A pesquisa em produtos naturais é uma das áreas mais tradicionais da Química no Brasil, devido a fatores históricos amplamente discutidos $^{1}$ e à grande biodiversidade do país. A formação científica dos pesquisadores e a infraestrutura dos laboratórios são bastante adequadas para o desenvolvimento de pesquisa de qualidade na área. A maioria dos trabalhos está voltada para o isolamento e a identificação de substâncias, muitas vezes associada a ensaios biológicos ou estudos quimiotaxonômicos. Estes trabalhos têm gerado um número significativo de publicações em revistas indexadas internacionais e nacionais, além de contribuir expressivamente para a formação de recursos humanos competentes na área de produtos naturais. Porém, algumas diferenças são observadas quando as pesquisas brasileiras em produtos naturais são comparadas com as desenvolvidas no exterior. Uma das principais diferenças está relacionada com a forte inserção dos produtos naturais na área biológica, fato que nas pesquisas brasileiras é observado quase que exclusivamente na busca de substâncias bioativas. Mesmo assim, a baixa produtividade em relação à identificação de produtos naturais efetivamente úteis como ferramentas de pesquisas biológicas ou como candidatos a protótipos de fármacos e outras substâncias de interesse sugere que a integração entre a Biologia e a Química não tem sido feita de forma eficiente na pesquisa em produtos naturais no Brasil.

Neste sentido, o objetivo principal deste artigo é mostrar como alguns dos avanços na Biologia, especialmente na Biologia Molecular, podem ser associados à pesquisa em produtos naturais e vice-versa, ou seja, como os produtos naturais podem ser inseridos nas pesquisas biológicas de forma eficiente, contribuindo para a área de Biologia Química. Além disso, aspectos da política científica no país e seu impacto na pesquisa também são discutidos.

\section{OS PRODUTOS NATURAIS NA ERA PÓS-GENÔMICA E A BIOLOGIA QUÍMICA}

As áreas de pesquisa mais estimulantes e vibrantes geralmente estão nas interfaces entre disciplinas que tradicionalmente estiveram separadas. No caso das ciências químicas e biológicas, estas interfaces vêm sendo exploradas com sucesso por mais de um sécu-

*e-mail: mtpupo@fcfrp.usp.br lo. As áreas de farmacologia, bioquímica, química e biofísica estão integradas à pesquisa biomédica e têm tido um impacto profundo na saúde humana. A Biologia Química (“Chemical Biology”) é uma nova variante nesta interface. Esta área multidisciplinar cresceu imensamente devido aos avanços revolucionários que ocorreram na biologia molecular nas duas últimas décadas. A habilidade na manipulação das moléculas de DNA e sua expressão possibilitaram avanços significativos no entendimento de vias biológicas centrais e enzimáticas. Estes progressos, associados aos novos métodos poderosos e mais baratos de síntese química bem como aos métodos modernos e eficientes de purificação e caracterização química, têm ligado as ciências biológicas e químicas de forma sem precedente ${ }^{2}$.

A Biologia Química caracteriza-se pelo enfoque dado às pequenas moléculas e sua utilização nos estudos de processos biológicos, enquanto a Química Biológica tem como foco principal de estudo as macromoléculas, principalmente as proteínas e os mecanismos enzimáticos. O princípio fundamental da vida envolve a transferência de informação fluindo entre macromoléculas (DNA $\rightarrow$ RNA $\rightarrow$ proteínas), porém a vida não existiria apenas com macromoléculas. Uma descrição mais abrangente deste princípio deve incluir as pequenas moléculas e o papel que elas desempenham em diversos aspectos vitais fundamentais, incluindo as origens da vida, memória, cognição, aspectos sensoriais, sinalização, entendimento dos circuitos celulares e tratamento das doenças, entre outros. Assim, a Biologia Química tem como objetivo ampliar o conhecimento sobre a importância de pequenas moléculas em processos vitais ${ }^{3}$.

Schreiber ${ }^{3}$ aponta quatro grandes desafios para a área de Biologia Química:

1. decifrar as origens da vida e criar formas alternativas de vida;

2. completar o inventário de todas as moléculas naturais existentes;

3. identificar uma pequena molécula moduladora para cada função de todas as proteínas humanas;

4. criar uma interação efetiva entre as pesquisas básicas e clínicas, através da ligação sistemática da variação genética nas células à habilidade de pequenas moléculas provocarem mudanças fenotípicas celulares.

A pesquisa em produtos naturais tem se inserido tradicionalmente na interface entre química e biologia, e pode contribuir significativamente em pelo menos três dos grandes desafios da Biologia Química. A maioria dos trabalhos em produtos naturais tem contribuído para se alcançar o segundo desafio da Biologia Química, 
envolvendo a busca de novas substâncias e moléculas bioativas. Tais trabalhos sempre terão espaço, uma vez que muitas das fontes de produtos naturais são ainda pouco exploradas.

As plantas e microrganismos cultiváveis são as principais fontes de moléculas biologicamente ativas e terapeuticamente úteis, embora as triagens contínuas destas fontes frequentemente levem a altos índices de reisolamento de substâncias já caracterizadas. Fontes de biodiversidade menos exploradas ou inexploradas estão frequentemente associadas à nova diversidade química ${ }^{4}$. Entre estas fontes podem ser citados os microrganismos extremofílicos, que vivem em condições ambientais de temperaturas anormalmente altas ou baixas, de escassez de umidade ou luminosidade, além dos microrganismos endofíticos e marinhos. Newman e Cragg ${ }^{5}$, em sua mais recente revisão publicada no Journal of Natural Products, também enfatizam que a pesquisa em química de produtos naturais microbianos deve ser expandida significativamente. Porém, estima-se que apenas cerca de $1 \%$ dos microrganismos seja cultivável pelos métodos frequentemente usados em laboratório. Assim, a grande maioria de microrganismos não cultiváveis certamente está relacionada à elevada diversidade química e deve ser considerada na busca de novos produtos naturais ${ }^{6}$.

Os genomas de toda a microbiota encontrada na natureza são denominados em conjunto de metagenoma ${ }^{7}$. Técnicas de isolamento do metagenoma do solo permitem que o DNA de toda comunidade microbiana seja diretamente extraído do ambiente, eDNA (do inglês "environmental DNA"). Através da expressão heteróloga do eDNA em hospedeiros facilmente cultiváveis, como Escherichia coli, os respectivos produtos naturais codificados pelo metagenoma de microrganismos não cultiváveis podem ser produzidos, isolados, identificados e avaliados biologicamente ${ }^{7}$. Como resultados da aplicação desta metodologia, podem ser citados os antibióticos: turbomicina A (1) e turbomicina B (2) ${ }^{8}$, derivados $N$-acila da tirosina $(3)^{6}$ e violaceína (4) $)^{9}$ (Figura 1), entre outros ${ }^{10}$. As estruturas de 1 e 2 foram confirmadas através dos dados de difração de raios-x dos sais de perclorato obtidos sinteticamente.
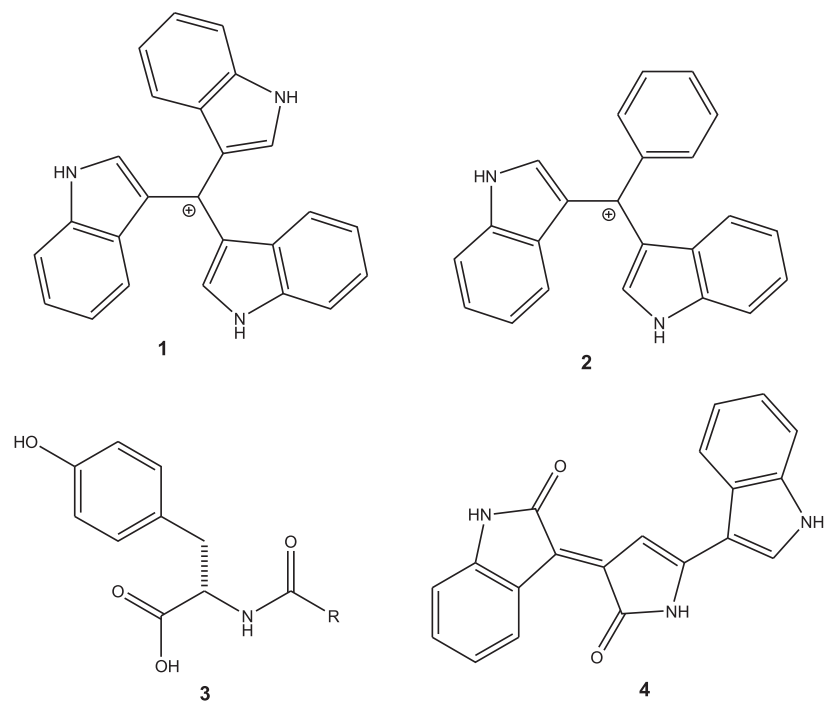

$\mathrm{R}=$ cadeias alquílicas $\mathrm{C}_{7}$ a $\mathrm{C}_{17}$, saturadas e insaturadas

Figura 1. Produtos naturais antibióticos isolados a partir de metagenoma

Os estudos com produtos naturais microbianos também mostraram que as bactérias apresentam uma surpreendente e elaborada capacidade de comunicação entre si e com outras espécies, como plantas e mamíferos ${ }^{11}$, valendo-se da biossíntese das chamadas moléculas sinalizadoras, as quais desempenham papel fundamental na sobrevivência bacteriana e sua interação nos habitats naturais ${ }^{12}$. Estas moléculas sinalizadoras ("quorum-sensing") são usadas, por exemplo, para regular bioluminescência, fatores de virulência, formação de biofilme, esporulação, motilidade, biossíntese de antibióticos, entre outras funções ${ }^{12,13}$. As pesquisas com moléculas sinalizadoras são mais concentradas em bactérias devido ao vasto conhecimento sobre as $\mathrm{N}$-acil-homoserina lactonas e peptídeos, principais exemplos de sinalizadores em bactérias Gram-negativo e Gram-positivo, respectivamente ${ }^{13}$. No entanto, o tirosol e o farnesol já foram identificados como moléculas sinalizadoras em Candida albicans $^{14}$. Uma vez que estas moléculas regulam importantes processos nos organismos produtores, a pesquisa nesta área é bastante promissora para o entendimento do ciclo de vida dos microrganismos e para a descoberta de moléculas bioativas, as quais possam inclusive regular a virulência de microrganismos patogênicos.

Neste contexto, as técnicas microbiológicas e de biologia molecular para o isolamento, identificação, cultivo e manutenção dos microrganismos são essenciais para o trabalho dos químicos de produtos naturais. A inserção destas técnicas nos laboratórios de produtos naturais, através do aprendizado ou de colaborações efetivas com microbiologistas e biólogos moleculares, pode contribuir de forma mais expressiva ao segundo grande desafio da Biologia Química.

A importância dos produtos naturais na descoberta e desenvolvimento de fármacos é bem documentada ${ }^{5,15,16}$, estando a pesquisa nesta área inserida tanto no segundo quanto no terceiro desafio da Biologia Química. Apesar dos progressos nas técnicas de sequenciamento de vários genomas, do acesso aos compostos diversificados de coleções combinatórias, do planejamento racional baseados nas estruturas de proteínas puras, dos ensaios em larga escala (high-throughput screening, HTS) e dos métodos computacionais, observou-se uma queda de produtividade na indústria farmacêutica justamente durante um período de dramático crescimento e investimentos em pesquisa e desenvolvimento ${ }^{17}$. O último grande pico de descoberta e desenvolvimento de fármacos culminou com a introdução de 53 novos fármacos em $1996^{18}$. Considerando-se que o período de desenvolvimento de um fármaco varia de 10 a 14 anos, aquela alta produtividade está relacionada às pesquisas realizadas no início dos anos 80 . Neste contexto, a literatura recente tem sugerido um retorno à pesquisa em produtos naturais para a retomada do crescimento da produtividade pela indústria farmacêutica ${ }^{4,5,16}$. As novas tecnologias introduzidas para a descoberta e desenvolvimento de fármacos, como química combinatória e HTS, não tiveram o impacto esperado na produtividade, apesar das vantagens de serem mais rápidas e de menor custo, além de definirem de forma clara a propriedade intelectual ${ }^{19}$. A química cominatória, por exemplo, foi responsável pelo surgimento de apenas uma nova entidade química de domínio público, o agente antitumoral sorafenibe (Nexavar, Bayer), aprovada pelo FDA em $2005^{5}$, enquanto os produtos naturais contribuíram de forma mais significativa para o desenvolvimento de vários fármacos originais ${ }^{5,15,16}$.

Hoje já se considera que uma pequena coleção de compostos mais "inteligentes" pode ter maior valor que uma grande mistura heterogênea produzida aleatoriamente. Neste sentido, os produtos naturais apresentam estruturas privilegiadas do ponto de vista biológico, uma vez que evoluíram em conjunto com as proteínas durante suas biossínteses e também quando apresentavam atividades biológicas. Além disso, os produtos naturais apresentam uma ampla e complexa diversidade química, com propriedades similares aos fármacos em uso ${ }^{20}$. Como as reações na natureza são altamente influenciadas pela função, cada produto natural deve ter um receptor biológico e, portanto, o receptor será potencialmente um alvo para fármacos. Essa premissa de que os produtos naturais apare- 
cem na natureza para interagir com um determinado receptor (biomacromolécula) explicaria o enorme custo bioquímico para a produção destas moléculas, e a partir dela todos os produtos naturais poderiam ser considerados como estruturas químicas biologicamente validadas ${ }^{21}$.

Uma coleção de compostos com diversidade e complexidade estrutural é de fundamental importância para aumentar a possibilidade de sucesso de triagens em ensaios fenotípicos envolvendo células ou organismos inteiros, onde qualquer uma das macromoléculas presentes pode representar um potencial alvo ${ }^{22}$. Adicionalmente, muitos processos biológicos são extremamente dependentes de interações proteína-proteína, e inúmeras pequenas moléculas que interferem nestas interações são produtos naturais estruturalmente complexos. Como consequência, uma das estratégias mais promissoras para obtenção de diversidade química é justamente associar a capacidade de produção de compostos da química combinatória à diversidade química e complexidade estrutural dos produtos naturais, produzindo coleções combinatórias menores derivadas da qualidade dos produtos naturais, uma abordagem denominada Síntese Orientada pela Diversidade (do inglês "Diversity Oriented Synthesis", DOS) $)^{22,23}$

Na era pós-genômica, com todos os avanços nos conhecimentos biológicos, tanto os laboratórios acadêmicos estão redescobrindo o valor dos compostos modulatórios para explorar processos biológicos quanto as indústrias farmacêuticas estão considerando a pesquisa biológica baseada em "probes" químicos ${ }^{17}$, com o objetivo de encontrar novos alvos terapêuticos e também pequenas moléculas que possam modular suas atividades.

Obviamente, estas pequenas moléculas também podem ser exploradas para a descoberta de novos alvos ${ }^{24}$. Esta abordagem é denominada "Farmacologia Reversa" ou "Genética Química" ("Chemical Genetics"), área de pesquisa que requer coleções de compostos como ponto inicial para os estudos ${ }^{21}$, na qual os produtos naturais também se inserem de forma importante para que o terceiro desafio da Biologia Química seja atingido.

A Genética Química pode ser definida como o uso sistemático de pequenas moléculas para alterar a função de proteínas às quais elas se ligam, explorando os avanços recentes em robótica, química combinatória, ensaios em larga escala (HTS) e bioinformática. De forma resumida, a Genética Química envolve um estudo genético usando ferramentas químicas ${ }^{21}$. É uma abordagem complementar à genética, amplamente usada em biologia, que altera a função de proteínas através de mutações em genes de interesse, seja por inativação (deleção ou "knock-out") ou ativação (oncogênicos). A Genética Química envolve a exposição de células a uma coleção de compostos de qualquer origem (natural ou sintética) para a seleção da molécula que induz a mudança fenotípica de interesse, seguida da identificação da proteína responsável (alvo macromolecular) pela alteração fenotípica ${ }^{21}$. Assim, a genética química opera no sentido do efeito para a causa, ou seja, do fenótipo para o genótipo, e o mecanismo de ação do composto é determinado posteriormente. Este é o paradigma mais antigo da descoberta de fármacos.

O termo Genética Química foi introduzido devido à especificidade com que alguns produtos naturais interagem com proteínas, levando a efeitos comparáveis aos de knock-outs em genes ${ }^{25}$. Portanto, alguns produtos naturais constituem poderosas ferramentas para o estudo de processos biológicos, podendo contribuir com o terceiro desafio da Biologia Química através do entendimento de vias bioquímicas e identificação de novas proteínas. Embora historicamente bem sucedida, esta abordagem de avaliação fenotípica tem algumas limitações para os produtos naturais, principalmente quando se buscam substâncias ativas. Somente extratos que contenham as substâncias mais potentes e/ou abundantes irão apresentar resultados positivos, enquanto compostos menos abundantes ou moderadamente ativos, embora potencialmente interessantes, podem não ser detectados. Somando-se a este fato, compostos citotóxicos podem mascarar efeitos fenotípicos sutis de outros compostos presentes na mistura bruta. Por fim, efeitos sinergísticos ou cooperativos entre compostos em misturas podem ser perdidos após os fracionamentos. Para atenuar estas limitações podem ser realizados pré-fracionamentos simples dos extratos, através de resinas adsorventes como Diaion HP-20, XAD, C-18 ou mesmo sílica gel, que levam à obtenção de frações menos complexas. Alguns laboratórios usam também sistemas de CLAE preparativo paralelo para separar um grande número de extratos brutos, possibilitando que amostras relativamente puras entrem nas triagens iniciais, aumentando a possibilidade de sucesso de identificação de novos produtos bioativos ${ }^{26}$.

Em contraste, a Genética Química Reversa envolve a seleção da proteína de interesse, triagem da coleção de compostos, identificação da molécula que interage com a proteína ("ensaios primários”) e posterior observação das consequências fenotípicas da exposição das células ao ligante em modelos de doença in vivo ("ensaios secundários"). Os efeitos farmacológicos do composto são associados com a ligação à proteína, e isto fornece informações sobre a função daquela proteína (da causa para o efeito, ou do genótipo para o fenótipo). Este é um dos paradigmas da descoberta de fármacos atualmente ${ }^{17}$.

As estratégias baseadas na Proteômica Química e na Proteômica Química Reversa são análogas às estratégicas de genética química e genética química reversa, porém o foco são os alvos protéicos de pequenas moléculas. Vale lembrar que a maioria dos alvos biológicos são proteínas. A proteômica química e a proteômica química reversa também podem ser usadas para a identificação de receptores de produtos naturais, completando a trilogia gene-proteína-ligante para que o terceiro desafio da Biologia Química seja atingido.

Proteômica é uma abordagem ampla para o entendimento da função, interações, modificações, localização e regulação de todas as proteínas expressas por uma célula. A Proteômica Química é semelhante a proteômica clássica, exceto pelo fato de que uma pequena molécula marcada é usada para isolar uma proteína única ou uma família de proteínas de um proteoma completo ${ }^{21}$. O marcador geralmente é um composto radioativo ou fluorescente, para permitir a visualização das proteínas ligadas em um gel de eletroforese, ou uma superfície de fase sólida, para permitir a purificação das proteínas por afinidade. Na proteômica reversa, o ponto de partida é o genoma ou o cDNA (transcriptoma) do organismo, não um extrato protéico. A Proteômica Química Reversa é análoga a proteômica reversa e utiliza uma pequena molécula biologicamente ativa e marcada para o isolamento dos fagos que apresentam proteínas capazes de se ligar à pequena molécula ${ }^{21}$. $\mathrm{O}$ ponto de partida na proteômica química reversa é o transcriptoma do fenótipo de interesse. A biblioteca de cDNA é clonada em um sistema de expressão e o proteoma marcado resultante é triado frente a uma pequena molécula.

Assim, o objetivo da Genética Química poderia ser resumido em "identificar uma pequena molécula associada a cada produto de gene" 25 e o da Proteômica Química em "encontrar um produto de gene para cada produto natural" ${ }^{21}$. Ambas as abordagens estão inseridas no terceiro desafio da Biologia Química.

Há diversos exemplos onde a avaliação dos efeitos fenotípicos de produtos naturais tem levado a importantes descobertas biológicas. A colchicina (5), que desestabiliza os microtúbulos, teve papel fundamental na descoberta da proteína tubulina do citoesqueleto ${ }^{27}$. Este produto natural marcou o início de uma longa história de utilização de pequenas moléculas para o estudo da biologia do citoesqueleto, levando à identificação de outros produtos naturais que interagem com componentes do citoesqueleto, como 
vimblastina, podofilotoxina, citocalasina $\mathrm{B}$, paclitaxel, dolastatina10 e epotilona $\mathrm{A}^{21}$. FK506 (tacrolimus, 6), ciclosporina (7) e rapamicina (8) são usadas para estudo de transdução de sinal. Os estudos com rapamicina levaram à descoberta da proteína FRAP, que media pontos de verificação ("checkpoints") do ciclo celu$\operatorname{lar}^{25}$. Geldanamicina (9), inibidor da Hsp90 e brefeldina A (10), disruptor de Golgi, foram inicialmente descobertos através de seus efeitos fenotípicos. Os alvos destes compostos foram posteriormente identificados, fornecendo informações importantes sobre suas funções em vários processos celulares ${ }^{26}$. Discodermolida (11) e lactacistina (12) também são produtos naturais que contribuíram com o estudo do fuso mitótico e sobre a progressão do ciclo celular dependente do proteassoma ${ }^{25}$.

As técnicas de biologia molecular permitem também que organismos sejam modificados geneticamente de forma rotineira em laboratório. Esta abordagem pode ser aplicada na pesquisa em produtos naturais para a obtenção de substâncias novas ou conhecidas, de interesse e/ou valor agregado.

A partir de experimentos realizados por Hopwood na década de 80 , um grande número de exemplos utilizando a técnica de biossíntese combinatória tem aparecido na literatura. Este procedimento, o qual é bem aceito como estratégia para aumentar a diversidade de produtos naturais, aplica métodos de engenharia genética para modificar os processos biossintéticos de produtos naturais e produzir novas estruturas usando a maquinaria biossintética existente em cada organismo. Esta possibilidade foi primeiramente demonstrada por Hopwood et al. ${ }^{28}$. Fazendo a clonagem de genes biossintéticos do antibiótico actinorodina (13) de Streptomyces coelicolor, Hopwood e colaboradores modificaram geneticamente os produtores de medermicina (14) e diidrogranaticina (15), respectivamente. O actinomiceto Streptomyces sp. AM-7161 modificado geneticamente produziu, além de medermicina, grandes quantidades de uma nova substância mederorrodina (16), a qual contém um grupo hidroxila adicional característico da actinorodina. Streptomyces violaceoruber Tü 22, modificado para produzir diidrogranaticina, produziu uma nova substância, diidrogranatirodina (17), preservando as configurações dos precursores nos estereocentros da nova molécula. Este trabalho representa a primeira utilização do conceito de biossíntese combinatorial de produtos naturais e abriu uma nova perspectiva para a diversificação estrutural de produtos naturais de interesse ${ }^{28}$, contribuindo para o segundo e para o terceiro desafios da Biologia Química.

O quarto desafio da Biologia Química requer o estabelecimento de uma integração efetiva entre as pesquisas básicas e clínicas, e será facilitado pelos progressos obtidos nos segundo e terceiro desafios $^{3}$, justamente naqueles onde os produtos naturais exercem fundamental importância.

O primeiro desafio da Biologia Química é o mais audacioso e difícil de ser atingido, porém os avanços na área já permitem, por exemplo, a síntese química de sistemas alternativos aos ácidos nucleicos, seguida da comparação das suas propriedades químicas com os ácidos nucleicos naturais, na tentativa de se entender as razões pelas quais estas estruturas foram selecionadas pela natureza como base molecular do sistema genético da vida ${ }^{29}$. Outra abordagem que se insere neste desafio envolve a adição de um grande número de novos aminoácidos sintéticos não essenciais aos códigos genéticos de organismos procariotos e eucariotos. A expansão sistemática dos códigos genéticos dos organismos vivos<smiles>COc1cc2c(c(OC)c1OC)-c1ccc(OC)c(=O)cc1[C@@H](NC(C)=O)CC2</smiles>

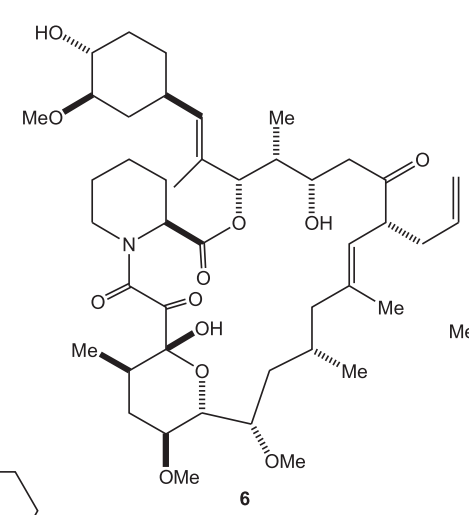

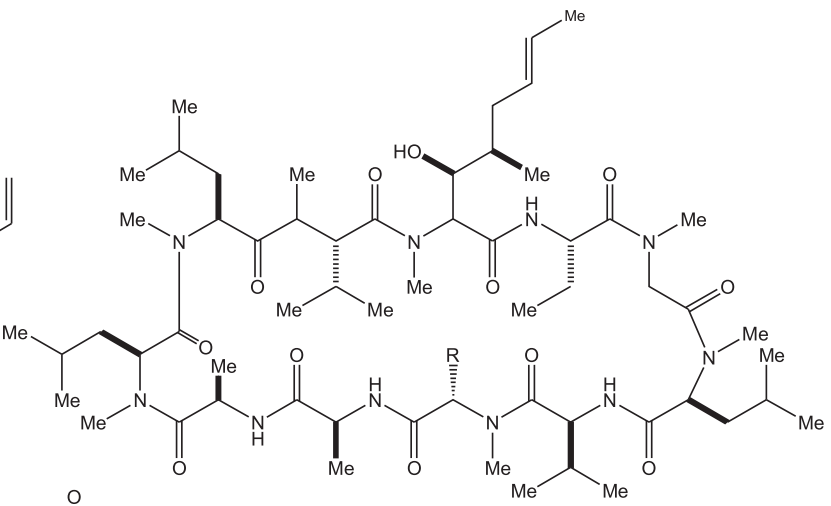<smiles>CO[C@H](C[C@@H]1CC[C@@H](C)[C@](O)(C(=O)C(=O)N2CCCCC2)O1)C(=O)O</smiles>

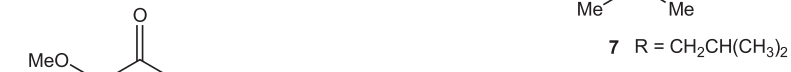

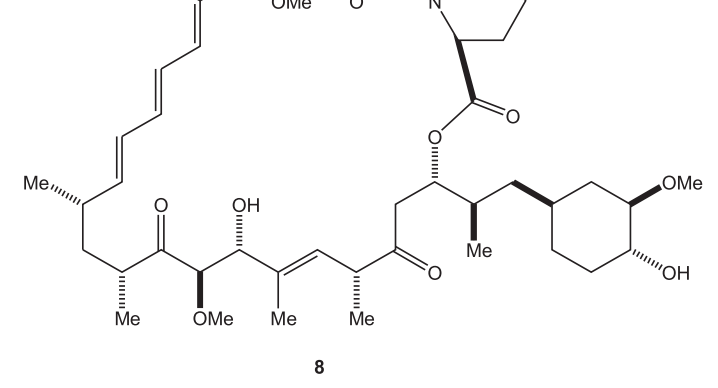

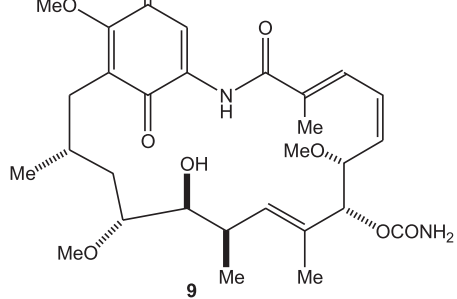

$7 \mathrm{R}=\mathrm{CH}_{2} \mathrm{CH}\left(\mathrm{CH}_{3}\right)_{2}$<smiles>CCC/C=C/[C@@H]1C[C@@H](O)CC1C/C=C/C(=O)OC(C)C</smiles>

10

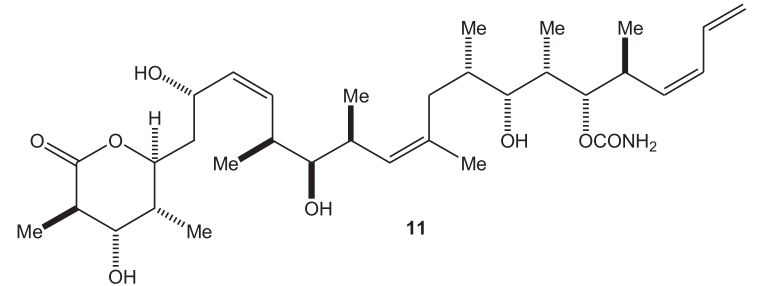<smiles>CC(=O)NC(CSC(=O)[C@@]1(C(O)C(C)C)NC(=O)[C@H](C)[C@@H]1O)C(=O)O</smiles>

12

Figura 2. Alguns produtos naturais importantes em Biologia Química 


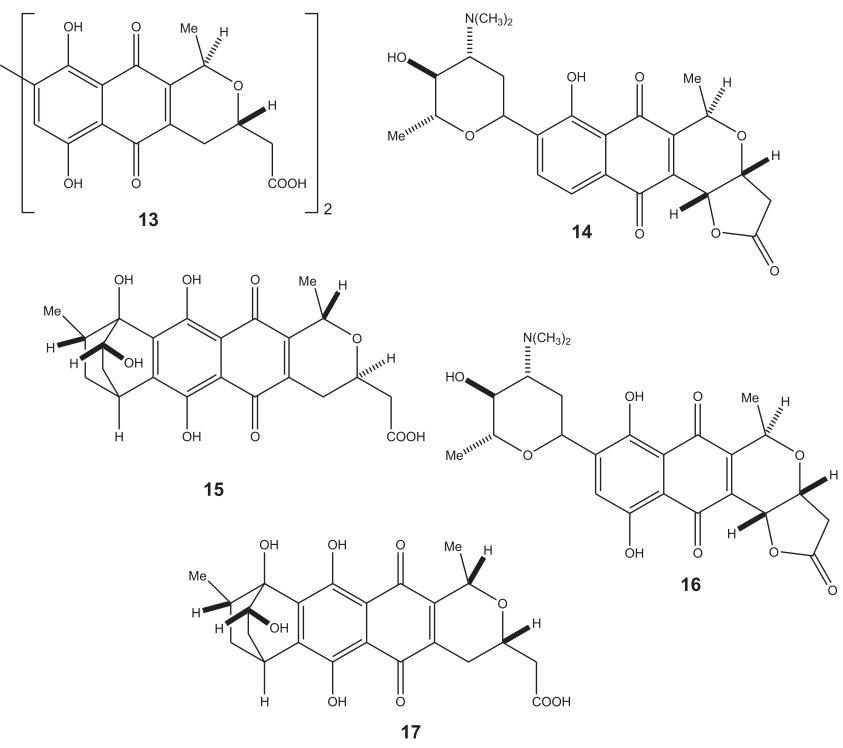

Figura 3. Exemplos de substâncias obtidas através de biossintese combinatória

poderá viabilizar, no futuro, a evolução de proteínas, ou até mesmo organismos inteiros, com propriedades novas e melhoradas ${ }^{30}$. Assim, o trabalho de químicos orgânicos sintéticos tem especial importância para que o primeiro desafio da Biologia Química seja compreendido e alcançado.

Embora os Biólogos Químicos sejam geralmente treinados e identificados como Químicos, a Biologia Química não existe sem a Biologia. Assim, a integração entre Química, Biologia e Medicina é fundamental para que a Biologia Química alcance seus desafios, o que certamente pode transformar a ciência e a sociedade.

Nos EUA a pesquisa em produtos naturais está fortemente inserida na área de Biologia Química e tem recebido apoio financeiro significativo pelos financiamentos do NIH ("National Institutes of Health"), incluindo seu "National Institute of General Medical Sciences" (NIGMS), há vários anos, principalmente através de grants (tipo R01) a pesquisadores ${ }^{2}$. Mais de $60 \%$ do orçamento de 2007, o qual está totalizado em US\$ 1.94 bilhões, estão destinados a grants deste tipo. As áreas de especial interesse ao NIH são anunciadas em forma de programas. Dentre as diversas áreas, a "Roadmaps's Molecular Libraries and Imaging Initiative" (MLII) tem o maior componente de Biologia Química. A espinha dorsal desta iniciativa é a "Molecular Libraries Screening Center Network" (MLSCN) e o associado "NIH Molecular Libraries Small Molecule Repository". O objetivo do MLSCN é oferecer ao setor público acesso à capacidade de triagem em larga escala necessária para a identificação de pequenas moléculas que podem ser otimizadas como "probes" químicos para o estudo da função de genes, células e vias bioquímicas. As atividades do MLSCN e iniciativas relacionadas são integradas através de uma base de dados de acesso público denominada PubChem ${ }^{31}$, que conecta informações sobre pequenas moléculas com bases de dados biomédicas desenvolvidas e mantidas pelo Centro Nacional para Informação Biotecnológica do NIH. A área de produtos naturais também está incluída no MLII, como "Novas metodologias para a química de produtos naturais". O NIH apresenta outras chamadas para produtos naturais. Em busca realizada no endereço eletrônico do $\mathrm{NIH}^{32}$ foram encontradas 25 chamadas ativas envolvendo produtos naturais, mostrando a importância da área nos EUA.

$\mathrm{O}$ crescimento e a importância desta área podem ser ainda destacados pelo lançamento recente de revistas específicas em Biolo- gia Química, como Current Opinion in Chemical Biology (1997), ChemBioChem: a European Journal of Chemical Biology (2000), BMC: Chemical Biology (2001), Nature Chemical Biology (2005) e ACS Chemical Biology (2006). A "Royal Society of Chemistry" apresenta uma opção de busca on-line desde 2002 sobre assuntos de Biologia Química publicados em suas diversas revistas.

\section{ALGUNS ASPECTOS DA PESQUISA EM PRODUTOS NATURAIS NO BRASIL}

A pesquisa moderna em produtos naturais no Brasil teve início em meados do século passado e tem sido foco de constantes revisões, indicando uma preocupação com a diversidade a ser pesquisada, a qualidade e objetividade dos trabalhos bem como sua divulgação no meio científico ${ }^{1,33,34}$.

Há 27 anos, Gottlieb and Mors ${ }^{34}$ ressaltavam a urgência do despertar dos cientistas brasileiros para uma pesquisa mais aplicada dos produtos naturais e suas propriedades etiotrópicas (atividade contra organismos causadores de doenças). Visionaram aplicações mais práticas como resultado daquelas investigações fitoquímicas, dando exemplos das famílias de plantas nacionais mais estudadas e com grande potencial biológico. Atualmente, a busca das propriedades curativas de plantas a partir de seus constituintes isolados, "princípios ativos", traduz uma visão reducionista no que diz respeito à pesquisa científica sobre plantas medicinais, podendo esta mesma visão ser estendida a outros reinos estudados sob a mesma ótica. É necessário que se desenvolva uma interdisciplinaridade envolvendo todos os conhecimentos da cultura popular e científica, com cooperações firmadas entre grupos, para se estabelecer um referencial teórico como alicerce à produção do conhecimento científico, observando seus possíveis reflexos na maneira do homem conhecer, lidar e apropriar-se da natureza ${ }^{35} \mathrm{e}$, fundamentalmente, reverter a aquisição do saber em tecnologia utilizável.

Apesar de bem estabelecida no país, com pesquisadores de excelente nível científico e laboratórios equipados para o desenvolvimento de pesquisa de ponta em química de produtos naturais, observa-se que a maior parte da produção literária da comunidade científica brasileira de Produtos Naturais dos últimos 5 anos tem sido focada no estudo de uma determinada espécie (por exemplo um vegetal), em busca de seus compostos ativos em relação a uma gama de efeitos biológicos tradicionais como citotóxico, antitumoral, inseticida, moluscicida, antimicrobiano, analgésico, antiespasmódico, antiinflamatório, antiparasitário, antioxidante e hipoglicemiante. No entanto, esta metodologia de pesquisa tem se mostrado pouco produtiva quanto à descoberta de novos candidatos a protótipos de fármacos ou ferramentas biológicas, pois tem esbarrado em vários fatores limitantes como, por exemplo, a insuficiente quantidade dos compostos isolados a qual impede o teste final para se descobrir a(s) substância(s) responsável pela atividade. Alvos enzimáticos, amplamente utilizados como modelo biológico de atividade no exterior, os quais exigem mínimas quantidades, ainda estão sendo pouco explorados no país, como se pode ver por duas recentes revisões sobre produtos naturais inibidores da acetilcolinesterase ${ }^{36}$, alvo importante no tratamento de sintomas associados à Doença de Alzheimer, e da enzima conversora da angiotensina ${ }^{37}$, alvo terapêutico moderno e eficaz no tratamento da hipertensão arterial, além das enzimas de parasitas na busca de substâncias candidatas a protótipos antichagásicos e antileishmanióticos ${ }^{38}$.

Além disto, a comunidade científica parece se contentar com resultados pouco expressivos para geração de publicações, em consequência dos critérios de avaliação dos órgãos de fomento, os quais exigem publicações como prova de produtividade. 


\section{Patentes}

Considerando-se que os investimentos em pesquisa e desenvolvimento geram expectativas de obtenção de direitos sobre os resultados, para se compensar o dinheiro gasto durante o trabalho, existe um pequeno número de patentes relacionadas com a área de Produtos Naturais registradas por brasileiros, cerca de 5,8\% das 738 patentes registradas relacionadas especificamente a plantas nativas brasilei$\operatorname{ras}^{39}$, apesar dos 207 grupos de pesquisa encontrados no diretório do $\mathrm{CNPq}$ na área de química de produtos naturais de plantas ${ }^{40}$. Em função dos ensaios biológicos mais realizados, as patentes nacionais se concentram principalmente nas formulações dermatológicas, antivirais, antitumorais, antiinflamatórias e antimicrobiais ${ }^{39}$. A lei de patentes nacional ${ }^{41}$ não aceita apenas a descoberta de um princípio ativo natural, mas requer aplicação industrial e novidade inventiva para o reconhecimento de uma patente nesta área. Seguindo esta linha, a maioria das patentes reclamada no exterior $(57,4 \%)$ concerne ao emprego de extratos/substâncias ativos na forma de composições farmacêuticas ${ }^{39}$ devido ao fato deste tipo de proteção ser reconhecido pela maioria dos países. O cientista brasileiro precisa aprender reconhecer a importância de proteger os resultados obtidos de sua pesquisa. Além disso, o aumento de cooperações universidade - indústria na área de $\mathrm{P} \& \mathrm{D}$ é essencial para que a produtividade neste campo floresça ainda mais e o "ouro verde" brasileiro seja protegido da biopirataria e renda frutos ${ }^{42}$.

\section{Fitoterápicos}

$\mathrm{O}$ crescente interesse por medicamentos oriundos de plantas medicinais, mais especificamente os fitoterápicos, a possibilidade de implementação da fitoterapia no sistema público de saúde nacional e, principalmente, as resoluções RDC n ${ }^{\circ} 17$ de 24/02/2000 e RDC n ${ }^{\circ} 48$ de $16 / 03 / 2004^{43}$, dispondo sobre o registro de fitoterápicos no Brasil, fizeram crescer o número de publicações referentes a etnofarmacologia, registrando-se as espécies mais popularmente conhecidas e utilizadas ${ }^{44}$, tanto entre populações indígenas quanto em urbanas, assim como a utilização de fitoterápicos em farmácias comunitárias e no sistema de saú$\mathrm{de}^{45}$. As espécies nativas mais citadas como de uso popular estão representadas nas famílias Bignoniaceae, Anacardiaceae, Asteraceae, Leguminosae, Annonaceae, Apocynaceae, Lamiaceae e Euphorbiaceae. No entanto, a maioria dos fitoterápicos regularizada pelo governo é de origem exótica. A $4^{\text {a }}$ edição da Farmacopéia Brasileira inclui 44 monografias de plantas medicinais, porém somente $25 \%$ são nativas ${ }^{46}$. Neste sentido, nota-se que a comunidade científica de Produtos Naturais apresentou grande número de trabalhos publicados em periódicos brasileiros (Revista Brasileira de Plantas Medicinais, Journal of the Brazilian Chemical Society, Revista Brasileira de Farmacognosia, Revista Brasileira de Ciências Farmacêuticas, Química Nova, Revista Brasileira de Farmácia e Memórias do Instituto Oswaldo Cruz) resultantes da pesquisa com cerca de 50 famílias, principalmente Leguminosae, Piperaceae, Asteraceae, Euphorbiaceae, Rubiaceae, Rutaceae, Anacardiaceae, Lamiaceae, Meliaceae, Bignoniaceae, Annonaceae, Solanaceae, Clusiaceae, Myrtaceae, Apocinaceae e Combretaceae, respectivamente em ordem decrescente de citações, dentre as quais muitas espécies vêm sendo empregadas pelo povo brasileiro ${ }^{47}$. Algumas das pesquisas foram direcionadas especificamente à determinação estrutural ${ }^{48}$, porém uma parte já incluiu ensaios sobre atividade biológica $^{49}$, estudos da via biossintética de compostos ativos ${ }^{50}$, análise quantitativa de marcadores quimiotaxonômicos para controle de qualidade $^{51}$, avaliação da qualidade do fitoterápico comercializado ${ }^{52}$, avaliação de segurança clínica e citotoxicidade ${ }^{53}$, interações medicamentosas entre fitoterápicos e fármacos ${ }^{54}$, síntese baseada em protótipo quimioterapêutico ${ }^{55}$, descontaminação de fitoterápicos ${ }^{56}$, suplemento alimentar $^{57}$, desenvolvimento de novas formulações ${ }^{58}$ entre outras. Porém, há ainda uma grande lacuna entre atividades biológicas descritas e uso popular, assim como uma carência de estudos quanto aos efeitos adversos, contra-indicação, toxicidade e validação da eficácia e segurança do fitoterápico nativo.

Em uma época em que as exigências em segurança, eficácia e qualidade, estabelecidas pelas agências regulamentadoras se tornam cada vez mais rígidas, a entrada dos fitoterápicos no mercado deve estar vinculada aos estudos científicos necessários para que a população tenha acesso a uma terapia alternativa de qualidade, a qual não é tão econômica quanta se pensa, visto que exige um razoável investimento nas pesquisas acima relacionadas. Considerando-se, ainda, a expansão mundial que os mercados de produtos derivados de plantas (fitoterápicos, suplementos alimentares, cosméticos, repelentes de insetos, corantes, etc.) vêm conquistando, nosso país, possuidor de grande biodiversidade, tem a oportunidade de entrar em mercados bilionários como o farmacêutico e o de suplementos alimentares, os quais movimentam cerca de 320 e 31 bilhões de dólares/ano, respectivamente ${ }^{59}$, bastando uma política mais ousada do governo, sem repetir erros de abandono de projetos importantes como o Programa de Pesquisa de Plantas Medicinais da $\mathrm{CEME}^{60}$, e uma maior objetividade na elaboração dos temas de pesquisa da comunidade científica.

\section{Produtos naturais marinhos e microbianos}

O Brasil é o segundo maior país em extensão de costa marinha, no entanto existem apenas 13 grupos que trabalham com produtos naturais marinhos registrados no diretório de grupos de pesquisa do $\mathrm{CNPq}^{40}$. Os estudos referentes aos produtos naturais de invertebrados marinhos iniciaram-se no Brasil há $45 \operatorname{anos}^{61}$, enquanto a pesquisa química de metabólitos dos microrganismos marinhos é mais recente, tendo início em 1999 com o isolamento de um derivado de aminoácido de uma espécie inédita de actnomiceto ${ }^{62}$. Os trabalhos publicados nos periódicos brasileiros têm se concentrado nas áreas de identificação estrutural dos compostos isolados e suas atividades principalmente em ensaios citotóxicos e antibióticos ${ }^{63}$.

A pesquisa de metabólitos secundários provenientes de fungos endofíticos teve início com o programa da FIOCRUZ sobre a ocorrência de fungos endofíticos em plantas medicinais e atividade biológica de seus extratos ${ }^{64}$, seguida pelos grupos da Universidade Federal de São Carlos e Universidade Estadula Paulista (UNESP) de Araraquara ${ }^{65}$. O grupo pioneiro no estudo de produtos naturais de bactérias endofíticas estabeleceu-se na Universidade de Ribeirão Preto (UNAERP), em colaboração com a Universidade de Bonn, na Alemanha ${ }^{66}$. No diretório do $\mathrm{CNPq}^{40}$, na área de produtos naturais de microrganismos, estão computados 31 grupos. Os trabalhos publicados estão na área de isolamento e síntese de metabólitos com atividade biológica ${ }^{67}$, biotecnologia e biotransformação ${ }^{68}$, controle biológico ${ }^{69}$ e bioprospecção ${ }^{70}$.

\section{Inseticidas}

Não é por acaso que os insetos são citados até na Bíblia (Livro de Êxodo) como "as pragas do Egito". Devido ao fato da maioria ser fitófaga, os insetos exercem forte influência sobre o equilíbrio ecológico e vêm causando prejuízos severos ao homem, sejam como transmissores de doenças ou como destruidores de lavouras ou grãos estocados. Além disso, os insetos têm se apresentado cada vez mais resistentes aos inseticidas empregados no seu controle e os produtos naturais surgem como uma alternativa na busca de novos modelos ativos e no controle biológico ${ }^{71}$.

No Brasil, pesquisas relacionadas ao controle químico da formiga cortadeira, Atta sexdens, e seu fungo simbionte, Leucoagaricus 
gongylophorus, com produtos naturais tiveram início quando se observou que o formigueiro alimentado diariamente com folhas de Ricinus communis apresentou uma diminuição de volume do "jardim" do seu fungo simbionte ${ }^{72}$. Desde então, vários extratos e substâncias naturais, assim como alguns compostos sintetizados baseados em produtos naturais, têm sido testados com o objetivo de se encontrar substâncias inseticidas com ação direta sobre as formigas ou indireta sobre os microrganismos que vivem em simbiose com as mesmas $^{73}$ e sobre as pectinases, enzimas do fungo simbionte, uma pesquisa mais recente ${ }^{74}$. Os produtos naturais também vêm sendo testados em Aedes aegypti, transmissor da dengue ${ }^{75}$, Spodoptera frugiperda, praga do milho e outras culturas ${ }^{76}$, abelhas ${ }^{77}$, Tuta $a b$ soluta, a praga do tomateiro ${ }^{78}$, Anticarsia gemmatalis, praga da soja ${ }^{79}$. Além disso, alguns grupos têm trabalhado na síntese e identificação de feromônios ${ }^{80}$, eletroantenografia ${ }^{81}$, com ensaios de inibição enzimática das proteases de insetos ${ }^{82}$ e na quantificação de substâncias inseticidas em plantas $^{83}$.

\section{Doenças negligenciadas}

Em 2009 a Doença de Chagas completará 100 anos desde a sua descrição por Carlos Chagas. É tão negligenciada que seu censo não muda há pelo menos 10 anos, o que podemos notar segundo estatística exibida pela WHO ("World Health Organization") ${ }^{84}$ e pela maioria dos artigos que dizem respeito ao Trypanosoma cruzi, o agente etiológico da doença, os quais repetem incessantemente o número de 16-18 milhões de pessoas infectadas desde $1997^{85}$.

Graças a um programa coordenado entre os países do Cone Sul, a transmissão da doença por vetor e transfusão sanguínea foi interrompida desde 1997 no Uruguai, no Chile em 1999 e em oito de doze estados endêmicos do Brasil em 2000, logo a incidência de novas infecções pelo T. cruzi em todo o continente americano teve uma redução de $70 \%$, porém a doença continua causando um grande impacto econômico no tratamento dos casos crônicos ${ }^{86}$. No Brasil muito se tem pesquisado sobre a doença, apresentando-se uma média de 170 artigos por ano desde 2002, de acordo com dados do ISI/Web of Knowledge ${ }^{87}$. Porém esta média está muito aquém do suficiente para a descoberta, por exemplo, de uma substância que possa ser substituta eficiente da quimioterapia tradicional e não funcional que emprega o nitroderivado benznidazol. Desde a determinação estrutural da enzima gGAPDH de $T$. $c r u z i i^{88}$, a identificação de cumarinas inibidoras ${ }^{89}$ e a complexação do inibidor chalepina, produto natural, com seu sítio ativo $0^{90}$, várias substâncias, principalmente de origem vegetal, têm sido testadas como potenciais inibidores seletivos para este alvo, em busca de novos protótipos de fármacos para o tratamento da doença ${ }^{38}$. Além disso, técnicas de aperfeiçoamento do ensaio com a enzima GAPDH e compreensão do mecanismo de interação entre o parasita e célula hospedeira estão sendo desenvolvidas ${ }^{91}$. Somando-se a estes esforços, outras enzimas do T. cruzi também estão sendo alvo de pesquisa na procura por possíveis inibidores, como a cisteína-protease ${ }^{92}$ e tripanotiona redutase ${ }^{93}$, assim como vários grupos estão empenhados na pesquisa de produtos naturais tripanocidas ${ }^{94}$ bem como na síntese baseada em produtos naturais bioativos ${ }^{95}$. Alguns estudos estão sendo realizados para se averiguar atividade mutagênica ${ }^{96}$ e testes in vivo ${ }^{97}$ de compostos com atividade promissora.

Em relação às leishmanioses, a média de artigos publicados é ainda menor, 120, e a soma das pesquisas relacionadas a produtos naturais cai na faixa de $2,5 \%$ da média. Algumas enzimas foram recentemente isoladas ou estruturalmente determinadas como a APRT de Leishmania tarentolae ${ }^{98}$, na qual já estão sendo testados alguns produtos naturais ${ }^{99}$, e a DHODH de L. major ${ }^{100}$, cujo grupo também está realizando ensaios de inibição com produtos naturais, principalmente originados de fungos (dados não publicados dos autores). Extratos de plantas, fungos, proteínas originadas do veneno de cobra e produtos naturais ou sintéticos baseados em produtos naturais também estão sendo submetidos a ensaios leishmanicidas ${ }^{101}$, mas nada comparado aos dados obtidos no exterior ${ }^{102}$. Vale ressaltar que a falta de métodos rápidos, seguros e confiáveis na pesquisa de leishmanicidas tem sido um dos pontos críticos para se avaliar os produtos naturais isolados ${ }^{103}$.

Os trabalhos de brasileiros publicados nas principais revistas de produtos naturais no exterior, como Journal of Natural Products e Phytochemistry, seguem a mesma linha dos artigos publicados em revistas brasileiras discutidos acima. Estes trabalhos quase sempre focalizam alguma atividade biológica associada à novidade estrutural. Em outras revistas mais abrangentes de química orgânica, como Journal of Organic Chemistry, Organic Letters, Tetrahedron e Tetrahedron Letters, há trabalhos tipicamente de produtos naturais envolvendo bioatividade, mas a grande maioria se refere à síntese de produtos naturais.

\section{DIFICULDADES E DESAFIOS}

Os projetos de pesquisa na área de Produtos Naturais têm sido pouco audaciosos em função de vários fatores, entre eles, o medo de dar errado. Não arriscando em projetos mais audaciosos o que se vê com frequiência são propostas basicamente iguais e que têm somente pequenos adendos ou focos que pouco vão acrescentar ao que se conhece. Sem propostas diferenciadas a área não cresce em qualidade e também não cumpre o seu papel de gerar produtos.

A área de Produtos Naturais tem uma grande interface com Biologia, principalmente biologia química, biotecnologia e biologia molecular. Desta interface podem surgir respostas a muitos processos que são mediados por pequenas moléculas, mas ainda há uma grande barreira para esses projetos e, infelizmente, muito do que poderia ser feito não está nos planos de pesquisadores da área.

Como alternativa para se realizar pesquisa de relevância na área de produtos naturais ficaram os trabalhos de bioprospecção e como em um passe de mágica, de repente, todos os pesquisadores passaram a atuar nesta área. Isto gerou alguns problemas, entre eles, a falta de preparação para essa tarefa está fazendo com que haja trabalhos que não passam por um rígido crivo de qualidade. Alguns dos bioensaios utilizados são de pouca confiança e consequientemente os resultados daí advindos. Comum entre esses resultados está a total falta de tratamento dos dados com estatística e até mesmo de controles confiáveis, inclusive controle positivo.

Adicione-se a esses problemas a legislação em vigor para acesso a recursos genéticos da biodiversidade e estaremos diante de um problema quase que sem solução para a área que tanto apostou na bioprospecção. Há hoje pesquisadores trabalhando de forma marginal, sem as famosas autorizações do CGEN e correndo o risco de até serem presos, ou mesmo terem que responder a processos judiciais, por falta de permissão para o trabalho com material da nossa flora e fauna.

Os projetos via de regra estão engessados e, em muitos casos, a falta de foco de alguns representa grande engessamento para outros. Em certas agências de apoio à pesquisa, como a FAPESP, alterar os rumos iniciais de um projeto sem a "anuência" explícita dos assessores pode gerar uma enorme dificuldade para bolsista e seu orientador. Com cartas e outras justificativas, a alteração do previsto inicialmente deve satisfazer o quase que doentio direito de interferirem nos projetos, que os assessores julgam ter. Este procedimento dificulta o que deveria ser elementar, cortar ou alterar na base um projeto, antes de grandes investimentos de tempo e dinheiro. $\mathrm{O}$ fato de ter tido um projeto aprovado para apoio pelas agências de fomento não significa que ele tenha que dar certo, apesar de ser 
desejável que dê.

Outro fator de grande relevância para o desenvolvimento está na formação dos profissionais ali atuantes. Muitos dos egressos de programas de pós-graudação estão simplesmente replicando as áreas de pesquisa de seus ex-orientadores e com pouca imaginação. Poucos alunos estão obtendo seus doutorados ou mesmo saindo para o exterior para o pós-doutorado, o que pode ser claramente observado pelas estatísticas das agências de fomento. Possíveis explicações para esta constatação vão desde dificuldades financeiras para se viver no exterior - os valores das bolsas nem sempre permitem aos bolsistas terem uma vida razoável em um grande centro - ou mesmo dificuldades banais e lamentáveis como não conseguir aprovação mínima em provas de inglês e outras línguas. Dificuldades financeiras para se viver em um grande centro têm levado os bolsistas a optarem por pequenas cidades que nem sempre contam com instituições de renome.

Outro problema que não está confinado à área de Produtos Naturais, mas que traz consequiências sérias, é o tempo cada vez mais curto para obtenção dos graus de mestre e doutor. É inegável que a pesquisa universitária está baseada na presença de pós-graduandos, que cada vez se sentem mais pressionados pelo tempo para desenvolverem seus projetos e como consequiência qualquer projeto diferenciado, está fadado ao insucesso. Ou os alunos não vão querer este tipo de desafio por conta da dificuldade e insegurança com relação à finalização em tempo hábil, ou se enfrentarem o desafio chegarão ao final, se chegarem, com a sensação de culpa pelo insucesso. Há ainda que se considerar que em um sistema fortemente paternalista, no qual poucos alunos se submetem a trabalhar sem bolsas, não sobram alternativas para aqueles alunos que ultrapassam os tempos previstos. Seguindo esta lógica, o que determina a finalização de um projeto não é a sua contribuição ao conhecimento e/ou esclarecimento de determinadas questões, mas o tempo.

Adicione-se a isto o fato de que há uma forte tendência nas agências, diga-se principalmente CAPES, a interpretarem que tempos mais longos significam desmérito para os cursos de pós-graduação, o que nem sempre é verdade.

A solução para os problemas apontados está em um esforço conjunto de toda a comunidade, pois estes vários fatores que contribuem para o aumento de problemas precisam ser atacados como um todo e não dependem de atitudes isoladas. O que certamente pode ser feito a qualquer momento é a iniciativa de cada um para que seus projetos sejam mais bem focados e que possam contribuir, não só para a formação de recursos humanos, mas também para explicar os inúmeros processos em que estão envolvidos um infindável número de moléculas com papel fundamental para existência da vida. Neste processo os produtos naturais, sejam de pequenas ou macromoléculas, têm importância fundamental, o que por si já se justifica como área de pesquisa de extrema relevância para qualquer país.

\section{CONCLUSÕES}

As pequenas moléculas constituem ferramentas extremamente valiosas para o entendimento de processos biológicos e são essenciais nas pesquisas em Biologia Química. A natureza é a mais promissora fonte destas moléculas, fornecendo-as como ocorrem nos organismos vivos (seus produtos naturais) ou servindo de inspiração para a síntese orgânica, a qual pode tirar proveito destas estruturas químicas elaboradas e selecionadas através de longa evolução para produzir novos compostos com maiores chances de sucesso. Com os avanços obtidos pela Biologia Molecular, é possível atualmente identificar genes responsáveis pela biossíntese de produtos naturais, interferir em suas funções e inserí-los em outros organismos para a expressão de metabólitos. Desta forma, as pesquisas em
Produtos Naturais e em Síntese Orgânica podem trilhar caminhos diferentes daqueles tradicionalmente já bem estabelecidos. Porém, isto requer a integração efetiva e o diálogo comum entre os pesquisadores das áreas de Química e Biologia. As competências científicas nas duas áreas são bem estabelecidas individualmente no país. O momento é de associar estas competências em busca de soluções e/ou entendimento de problemas biológicos mediados por pequenas moléculas. Para isso, é necessária ousadia na elaboração de projetos inovadores por parte dos pesquisadores e maior receptividade por parte das agências de fomento à pesquisa e seus assessores, o que pode conduzir a um futuro bastante promissor para a área.

\section{AGRADECIMENTOS}

Os autores agradecem às agências de fomento à pesquisa CAPES, CNPq e FAPESP, pelo auxílio financeiro na forma de projetos e bolsas de pesquisa. Os autores também agradecem ao Professor Jon Clardy, da Harvard Medical School, pelas valiosas discussões.

\section{REFERÊNCIAS}

1. Pinto, A. C.; Silva, D. H. S.; Bolzani, V. S.; Lopes, N. P.; Epifânio, R. A.; Quim. Nova 2002, 25, 45.

2. Berg, J. M.; ACS Chem. Biol. 2006, 1, 547

3. Schreiber, S. L.; Nature Chem. Biol. 2005, 1, 64.

4. Clardy, J.; Walsh, C. T.; Nature 2004, 432, 829.

5. Newman, D. J.; Cragg, G. M.; J. Nat. Prod. 2007, 70, 461.

6. Brady, S. F.; Clardy, J.; J. Am. Chem. Soc. 2000, 122, 12903.

7. Handelsman, J.; Rondon, M. R.; Brady, S. F.; Clardy, J.; Goodman, R. M.; Chem. Biol. 1998, 5, R245; Rondon, M. R.; August, P. R.; Bettermann, A. D.; Brady, S. F.; Grossman, T. H.; Liles, M. R.; Loiacono, K. A.; Lynch, B. A.; MacNeil, I. A.; Minor, C.; Tiong, C. L.; Gilman, M.; Osburne, M. S.; Clardy, J.; Handelsman, J.; Goodman, R. M.; Appl. Environ. Microbiol. 2000, 66, 2541.

8. Gillespie, D. E.; Brady, S. F.; Bettermann, A. D.; Cianciotto, N. P.; Liles, M. R.; Rondon, M. R.; Clardy, J.; Goodman, R. M.; Handelsman, J.; Appl. Environ. Microbiol. 2002, 68, 4301.

9. Brady, S. F.; Chao, C. J.; Handelsman, J.; Clardy, J.; Org. Lett. 2001, 3, 1981.

10. Brady, S. F.; Chao, C. J.; Clardy, J.; J. Am. Chem. Soc. 2002, 124, 9968; Brady, S. F.; Clardy, J.; Angew. Chem. Int. Ed. 2005, 44, 7063; Brady, S. F.; Clardy, J.; Org. Lett.. 2005, 7, 3613.

11. Lyon, G. J.; Muir, T. W.; Chem. Biol. 2003, 10, 1007.

12. Miller, M. B.; Bassler, B. L.; Annu. Rev. Microbiol. 2001, 55, 165.

13. Bassler, B. L.; Cell 2002, 109, 421.

14. Nickerson, K. W.; Atkin, A. L.; Hornby, J. M.; Appl. Environ. Microbiol. 2006, 72, 3805; Chen, H.; Fujita, M.; Feng, Q.; Clardy, J.; Fink, G.R.; Proc Nat. Acad. Sci. 2004, 101, 5048.

15. Butler, M. S.; J. Nat. Prod. 2004, 67, 2141.

16. Newmann, D. J.; Cragg, G. M.; Snader, K. M. J.; J. Nat. Prod. 2003, 66, 1022 .

17. Thorpe, D. S.; Comb. Chem. High Throughput Screen. 2003, 6, 623.

18. Allan, E. L.; Drug Discov. World Winter 2002/3, 71.

19. Ortholand, J. Y.; Ganesan, A. Curr. Op. Chem. Biol. 2004, 8, 271.

20. Feher, M.; Schmidt, J. M.; Chem. Inf. Comput. Sci. 2003, 43, 218.

21. Piggot, A. M.; Karuso, P.; Comb. Chem. High Throughput Screen. 2004, 7, 607; Walsh, D. P.; Chang, Y. T.; Chem. Rev. 2006, 106, 2476.

22. Schreiber, S. L.; Science 2000, 287, 1964.

23. Borman, S.; Chem. Eng. News 2002, 80, 23; Burke, M. D.; Schreiber, S. L.; Angew. Chem. Int. Ed. 2004, 43, 46.

24. Harrigan. G. G.; Brackett, D. J.; Boros, L. G.; Mini-Rev. Med. Chem. 2005, 5,13 .

25. Schreiber, S. L.; Bioorg. Med. Chem. 1998, 6, 1127.

26. Lokey, R. S.; Curr. Op. Chem. Biol. 2003, 7, 91.

27. Shelanski, M. L.; Taylor, E. W.; J. Cell Biol. 1967, 34, 549.

28. Hopwood, D.A.; Malpartida, F.; Kieser, H.M.; Ikeda, H., Duncan, J.; Fujii, I.; Rudd, B. A. M.; Floss, H. G.; Omura, S.; Nature 1985, 314, 642.

29. Eschenmoser, A.; Science 1999, 284, 2118.

30. Wang, L.; Schulz, P. G.; Angew. Chem. Int. Ed. 2005, 44, 34.

31. http://pubchem.ncbi.nlm.nih.gov, acessada em Fevereiro 2007.

32. http://grants.nih.gov/grants/guide, acessada em Março 2007. 
33. Braz-Filho, R.; Pure Appl. Chem. 1999, 71, 1663; Brito, A. R. M. S.; Brito, A. A. S.; J. Ethnopharmacol. 1993, 39, 53; Gottlieb, O. R.; Mors, W. B.; Quim. Nova 1979, 2, 31; Pinto, A. C.; Rezende, C. M.; Garcez, F. R.; Epifânio, R. A.; Quim. Nova 2003, 26, 966; Pinto, A. C.; Quím. Nova 1995, 18,608 .

34. Gottlieb, O. R.; Mors, W. B.; J. Agric. Food Chem 1980, 28, 196.

35. Vasconcellos, A. G.; Branquinho, F. B.; Sanches, C.; Lage, C. L. S.; Rev. Bras. Farmacogn. 2002, 12, 103.

36. Barbosa Filho, J. M.; Medeiros, K. C. P.; Diniz, M. F. F. M.; Batista, L. M.; Athayde-Filho, F.; Silva, M. S.; Cunha, E. V. L.; Almeida, J. R. G. S.; Quitans-Júnior, L. J.; Rev. Bras. Farmacogn. 2006, 16, 258.

37. Barbosa Filho, J. M.; Martins, V. K. M.; Rabelo, L. A.; Moura, M. D.; Silva, M. S.; Cunha, E. V. L.; Souza, M. F. V.; Almeida, R. N.; Medeiros, I. A.; Rev. Bras. Farmacogn. 2006, 16, 421.

38. Alvim Júnior, J.; Dias, R. L. A.; Castilho, M. S.; Oliva, G.; Correa, A. G.; J. Braz. Chem. Soc. 2005, 16, 763; Moraes, V. R. S.; Tomazela, D. M.; Ferracin, R. J.; Garcia, C. F.; Sannomiya, M.; Soriano, M. P. C.; Silva, M. F. G. F.; Vieira, P. C.; Fernandes, J. B.; Rodrigues Filho, E.; Magalhães, E. G.; Magalhães, A. F.; Pimenta, E. F.; Souza, D. H. F.; Oliva, G.; J. Braz. Chem. Soc. 2003, 14, 380

39. Moreira, A. C.; Muller, A. C. A.; Pereira Júnior, N.; Antunes, A. M. S.; World Patent Information 2006, 28, 34.

40. Diretório dos grupos de pesquisa do CNPq. http://dgp.cnpq.br/ buscaoperacional/, acessada em Março 2007. Base corrente. Grupos. Palavra chave: química de produtos naturais.

41. Lei 9.279 de 14 de maio de 1996. Disponível em: http://www.biopirataria.org/ artigos/Lei_de_Patentes.pdf, acessada em Março 2007.

42. Moreira, A. C.; Pereira Júnior, N.; Antunes, A. M. S.; Rev. Bras. Pl. Med. 2005, 8, 85; Simões, C. M. O.; Schenkel, E. P.; Rev. Bras. Farmacogn. 2002, 12,35 .

43. Resolução RDC n ${ }^{\circ} 17,24 / 02 / 2000$. Ministério da Saúde. Agência Nacional da Vigilância Sanitária. Dispõe sobre o registro de medicamentos fitoterápicos. Diário Oficial da União 25/02/2000; Resolução RDC n ${ }^{\circ} 48$, 16/03/2000. Ministério da Saúde. Agência Nacional da Vigilância Sanitária. Dispõe sobre o registro de medicamentos fitoterápicos. Diário Oficial da União 18/03/2004.

44. Cechinel Filho, V.; Ouim. Nova 2000, 23, 680; Macedo, M.; Ferreira, A. R.; Rev. Bras. Farmacogn. 2004, 14, 40; Morais, S. M.; Dantas, J. D. P.; Silva, A. R. A.; Magalhães, E. F.; Rev. Bras. Farmacogn. 2005, 15, 169; Nunes, G. P.; Silva, M. F.; Resende, U. M.; Siqueira, J. M.; Rev. Bras. Farmacogn. 2003, 13, 83; Pereira, R. C.; Oliveira, M. T. R.; Lemos, G. C. S.; Rev. Bras. Farmacogn. 2004, 14, 37; Torres, A. R.; Oliveira, R. A. G.; Diniz, M. F. F. M.; Araújo, E. C.; Rev. Bras. Farmacogn. 2005, 15, 373; Vendruscolo, G. S.; Rates, S. M. K.; Mentz, L. A.; Rev. Bras. Farmacogn. 2005, 15, 361; Vila Verde, G. M.; Paula, J. R.; Carneiro, D. M.; Rev. Bras. Farmacogn. 2003, 13, 64 .

45. Michiles, E.; Rev. Bras. Farmacogn. 2004, 14, 16; Ogava, S. E. M.; Pinto, M. T. C.; Kikuch, T.; Menegueti, V. A. F.; Martins, D. B. C.; Coelho, S. A. D.; Marques, M. J. N. J.; Virmond, J. C. S.; Monteschio, P.; D’Aquino, M.; Marques, L.C.; Rev. Bras. Farmacogn. 2003, 13, 58; Oliveira, M. J. R.; Simões, M. J. S.; Sassi, C. R. R.; Rev. Bras. Pl. Med. 2006, 8, 39; Ribeiro, A. Q.; Leite, J. P. V.; Dantas-Barros, A. M.; Rev. Bras. Farmacogn. 2005, 15, 65; Silva, M. I. G.; Gondim, A. P. S.; Nunes, I. F. S.; Sousa, F. C. F.; Rev. Bras. Farmacogn. 2006, 16, 455.

46. Brandão, M. G. L.; Cosenza, G. P.; Moreira, R. A.; Monte-Mor, R. L. M.; Rev. Bras. Farmacogn. 2006, 16, 408.

47. Garcez, F. R.; Garcez, W. S.; Santana, A. L. B. D.; Alves, M. M.; Matos, M. F. C.; Scaliante, A. M.; J. Braz. Chem. Soc. 2006, 17, 1223; Salatino, A.; Salatino, M. L. F.; Negri, G.; J. Braz. Chem. Soc. 2007, 18, 11; Souza, T. M.; Moreira, R. R. D.; Pietro, R. C. L. R.; Isaac, V. L. B.; Rev. Bras. Farmacogn. 2007, 17, 71; Vieira, G. A. B.; Lima, M. A. S.; Bezerra, A. M. E.; Silveira, E. R.; J. Braz. Chem. Soc. 2006, 17, 43.

48. Paula, V. F.; Cruz, M. P.; Barbosa, L. C. A.; Quím. Nova 2006, 29, 213.

49. Salazar, K. J. M.; Paredes, G. E. D.; Lluncor, L. R.; Young, M. C. M.; Kato, M. J.; Phytochemistry 2005, 66, 573; Silva, V. C.; Lopes, M. N.; Bolzani, V. S.; Quím. Nova 2006, 29, 493.

50. Lopes, N. P.; Yoshida, M.; Kato, M. J.; Rev. Bras. Ciências Farm. 2004, 40, 53; Morandim, A. A.; Bergamo, D. C. B.; Kato, M. J.; Cavalheiro, A. J.; Bolzani, V. S.; Furlan, M.; Phytochem. Anal. 2005, 16, 282.

51. Beltrame, F. L.; Rodrigues Filho, E.; Barros, F. A. P.; Cortez, D. A.; Cass, Q. B.; J. Chromatogr. A 2006, 1119, 257; Nossack, A. C.; Celeghini, R. M. S.; Lanças, F. M.; Yariwake, J. H.; J. Braz. Chem. Soc. 2004, 15, 582; Oliveira, L. C. P.; Mause, R.; Nunomura, S. M.; J. Braz. Chem. Soc. 2005, 16, 1439; Zocoler, M. A.; Oliveira, A. J. B.; Sarragiotto, M. H.; Grzesiuk, V. L.; Vidotti, G. J.; J. Braz. Chem. Soc. 2005, 16, 1372.

52. Amaral, F. M. M.; Coutinho, D. F.; Ribeiro, M. N. S.; Oliveira, M. A.; Rev. Bras. Farmacogn. 2003, 13, 27.
53. Almeida, K. C.; Barbosa, T. R.; Silva, R. N. R.; Jacques, D. S.; Freire, R. B.; Rev. Bras. Farm. 2006, 87, 60; Carraschi, L.; Zaupa, C.; Tsuzuki, J. K.; Gabriel, M.; Ushirobira, T. M. A.; Kaneshima, E. N.; Silva, J. C.; Akimoto, L. S.; Marques, L. C. Rev. Bras. Farm. 2003, 84, 91; Corrêa, V. S. C.; Mayniè, J. C.; França, E. L.; Honório-França, A. C.; Rev. Bras. Pl. Med. 2006, 8, 26; Soares, A.K.A.; Carmo, G.C.; Quental, D.P.; Nascimento, D.F.; Bezerra, F.A.F.; Moraes, M.O.; Moraes, M.E.A.; Rev. Bras. Farmacogn. 2006, 16, 447.

54. Betoni, J. E. C.; Mantovani, R. P.; Barbosa, L. N.; Stasi, L. C. D.; Fernandes Júnior, A.; Mem. Inst. Oswaldo Cruz 2006, 101, 387; Cordeiro, C. H. G.; Chung, M. C.; Sacramento, L. V. S.; Rev. Bras. Farmacogn. 2005, 15, 272; Veiga Júnior, V. F.; Pinto, A. C.; Maciel, M. A. M.; Quím. Nova 2005, 28, 519 .

55. Figueiredo, I. M.; Santos, L. V.; Costa, W. F.; Carvalho, J. E.; Silva, C. C.; Sacoman, J. L.; Kohn, L. K.; Sarragiotto, M. H.; J. Braz. Chem. Soc. 2006, 17, 954; Logrado, L. P. L.; Silveira, D.; Romeiro, L. A. S.; Moraes, M. O.; Cavalcanti, B. C.; Costa-Lotufo, L. V.; Pessoa, C. O.; Santos, M. L.; J. Braz. Chem. Soc. 2005, 16, 1217.

56. Satomi, L. C.; Soriani, R. R.; Pinto, T. J. A.; Rev. Bras. Ciências Farmac. 2005, 41, 445 .

57. Magalhães, C. N. A.; Ferreira, I. A.; Gomes, M. G.; Borges, S. S. S.; Rev. Bras. Farm. 2004, 85, 61.

58. Arantes, A. B.; Luz, M. M. S.; Santos, C. A. M.; Sato, M. E. O.; Rev. Bras. Farm. 2005, 86, 61 .

59. Funari, C. S.; Ferro, V. O.; Rev. Bras. Farmacogn. 2005, 15, 178

60. Sant,,Ana, P. J. P.; Assad, A. L. D.; Ouím. Nova 2004, 27, 508.

61. Kelecom, A.; Ciência e Cultura 1997, 49, 321.

62. Berlinck, R. G. S.; Hadju, E.; Rocha, R. M.; Oliveira, J. H. H. L.; Hernández, I. L. C.; Seleghim, M. H. R.; Granato, A. C.; Almeida, E. V. R.; NuHez, C. V.; Muricy, G.; Peixinho, S.; Pessoa, C.; Moraes, M. O.; Cavalcanti, B. C.; Nascimento, G. G. F.; Thiemann, O. H.; Silva, M.; Souza, A. O.; Silva, C. L.; Minarini, P. R. R.; J. Nat. Prod. 2004, 67, 510.

63. Epifânio, R. A.; Pinheiro, L. S.; Alves, N. C.; J. Braz. Chem. Soc. 2005,16, 1367; Granato, A. C.; Oliveira, J. H. H. L.; Seleghim, M. H. R.; Berlinck, R. G. S.; Macedo, M. L.; Ferreira, A. G.; Rocha, R. M.; Hadju, E.; Peixinho, S.; Pessoa, C. O.; Moraes, M. O.; Cavalcanti, B. C.; Quim. Nova 2005, 28, 192; Hernández, I. L. C.; Macedo, M. L.; Berlinck, R. G. S.; Ferreira, A. G.; Godinho, M. J. L.; J. Braz. Chem. Soc. 2004, 15, 441.

64. Rodrigues, K. F.; Samuels, G. J.; J. Basic Microbiol. 2000, 39, 131; Rodrigues-Heerklotz, K. F.; Draudarov, K.; Heerklotz, J.; Hesse, M.; Werner, C.; Helv. Chim. Acta 2001, 84, 3766.

65. Santos, R. M. G.; Rodrigues Filho, E. Phytochemistry 2002, 61, 907; Teles, H. L.; Silva, H.; Castro-Gamboa, I.; Bolzani, V. S.; Pereira, J. O.; CostaNeto, C. M.; Haddad, R.; Eberlin, M. N.; Young, M. C. M.; Araújo, A. R.; Phytochemistry 2005, 66, 2363.

66. Pullen, C.; Schmitz, P.; Meurer, K.; Bamberg, D. D. V.; Lohmann, S.; França, S. D. C.; Groth, I.; Schlegel, B.; Mollmann, U.; Gollmick, F.; Grafe, U.; Leistner, E.; Planta 2002, 216, 162.

67. Barbosa, L. C. A.; Demuner, A. J.; Maltha, C. R. A.; Silva, O. S.; Silva, A. A.; Quím. Nova 2003, 26, 655; Borges, W. S.; Pupo, M. T.; J. Braz. Chem. Soc. 2006, 17, 929; Cafêu, M.C.; Silva, G.H.; Teles, H.L.; Bolzani, V.S.; Araújo, A.R.; Young, M.C.M.; Pfenning, L.H.; Quím. Nova 2005, 28, 691; Furtado, N. A.J. C.; Pupo, M. T.; Carvalho, I.; Campo, V. L.; Duarte, M. C. T.; Bastos, J. K.; J. Braz. Chem. Soc. 2005, 16, 1448; Marinho, A. M. R.; Rodrigues Filho, E.; Moitinho, M. L. R.; Santos, L. S.; J. Braz. Chem. Soc. 2005, 16, 280.

68. Baraldi, P. T.; Corrêa, A. G.; Quím. Nova 2004, 27, 421; Carrim, A. J. I.; Barbosa, E. C.; Vieira, J. D. G.; Braz. Arch. Biol. Technol. 2006, 49, 353; Oliveira, B. H.; Souza Filho, J. D.; Leal, P. C.; J. Braz. Chem. Soc. 2005, $16,210$.

69. Shiomi, H. F.; Silva, H. A. S.; Melo, I. S.; Nunes, F. V.; Bettiol, W.; Scientia Agricola 2006, 63, 32

70. Rosa, L. H.; Machado, K. M. G.; Jacob, C. C.; Capelari, M.; Rosa, C. A.; Zani, C. L.; Mem. Inst. Oswaldo Cruz 2003, 98, 967.

71. Arab, A.; Bento, J. M. S.; Neotropical Entomol. 2006, 35, 151; Viegas Júnior, C.; Quím. Nova 2003, 26, 390.

72. Hebling, M. J. A.; Maroti, O. S.; Bueno, O. C.; Silva, A. O.; Pagnnocca, F. C.; Bull. Entomol. Res. 1996, 86, 253.

73. Almeida, R. N. A.; PeHaflor, M. F. G. V.; Simote, S. Y.; Bueno, O. C.; Hebling, M. J. A.; Pagnnocca, F. C.; Fernandes, J. B.; Vieira, P. C.; Silva, M. F. G. F.; BioAssay 2007, 2, 1; Ambrozin, A. R. P.; Leite, A. C.; Bueno, F. C.; Vieira, P. C.; Fernandes, J. B.; Bueno, O. C.; Silva, M. F. G. F.; Pagnocca, F. C.; Hebling, M. J. A.; Bacci Júnior, M.; J. Braz. Chem. Soc. 2006, 17, 542; Biavatti, M. W.; Vieira, P. C.; Silva, M. F. G. F.; Fernandes, J. B.; Victor, S. R.; Pagnnocca, F. C.; Albuquerque, S.; Caracelli, I.; Zukerman-Schpector, J. Z.; J. Braz. Chem. Soc. 2002, 13, 66; Godoy, M. F. P.; Victor, S. R.; Bellini, A. M.; Guerreiro, G.; Rocha, W. C.; Bueno, O. 
C.; Hebling, M. J. A.; Bacci Júnior, M.; Silva, M. F. G. F.; Vieira, P. C.; Fernandes, J. B.; Pagnnocca, F. C.; J. Braz. Chem. Soc. 2005, 16, 669; Leite, A. C.; Bueno, F. C.; Oliveira, C. G.; Fernandes, J. B.; Vieira, P. C.; Silva M. F. G. F.; Bueno, O. C.; Pagnnocca, F. C.; Hebling, M. J. A.; Bacci Júnior, M.; J. Braz. Chem. Soc. 2005, 16, 1391; Victor, S. R.; Crisóstomo, F. R.; Bueno, F. C.; Pagnnocca, F. C.; Fernandes, J. B.; Corrêa, A. G.; Bueno, O. C.; Hebling, M. J. A.; Bacci Júnior, M.; Vieira, P. C.; Silva, M. F. G. F.; Pest Manag. Sci. 2001, 57, 603.

74. Gallo, M. B. C.; Zavan, C.; Almeida, R. N. A.; Vieira, P. C.; Bacci Júnior, M.; Pagnnocca, F. C.; Fernandes, J. B.; Silva, M. F. G. F.; Sobral, M.; Pest. Manag. Sci, submetido.

75. Laranja, A. T.; Manzato, A. J.; Bicudo, H. E. M. C.; Rev Saúde Pública 2006, 40,1112; Santos, R. P.; Nunes, E. P.; Nascimento, R. F.; Santiago, G. M. P.; Menezes, G. H. A.; Silveira, E. R.; Pessoa, O. D. L.; J. Braz. Chem. Soc. 2006, 17, 1027; Simas, N. K.; Lima, E. C.; Conceição, S. R.; Kuster, R. M.; Oliveira Filho, A. M.; Quím. Nova 2004, 27, 46.

76. Batista-Pereira, L. G.; Castral, T. C.; Silva, M. T. M.; Amaral, B.R.; Fernandes, J. B.; Vieira, P. C.; Silva, M. F. G. F.; Correa, A. G.; Z Naturforsch. C: J. Biosc. 2006, 61, 196; Gallo, M. B. C.; Rocha, W. C.; Cunha, U. S.; Diogo, F. A.; Silva, F. C.; Vieira, P. C.; Vendramim, J. D.; Fernandes, J. B.; Silva, M. F. D. F.; Batista-Pereira, L. G.; Pest Manag. Sci. 2006, 62, 1072.

77. Miranda, J. E.; Navickiene, H. M. D.; Nogueira-Couto, R. H.; De Bortoli, S. A.; Kato, M. J.; Bolzani, V. S.; Furlan, M.; Apidologie 2003, 34, 409.

78. Cunha, U. S.; Vendramin, J. D.; Rocha, W. C.; Vieira, P. C.; Pesquisa Agropec. Bras. 2006, 41, 1579.

79. Batista-Pereira, L. G.; Petacci, F.; Fernandes, J. B.; Corrêa, A. G.; Vieira, P. C.; Silva, M. F. G. F.; Malaspina, O.; Pest Manag. Sci 2002, 58, 503; Nascimento, I. R.; Murata, A. T.; Bortoli, S. A.; Lopes, L. M. X.; Pest Manag Sci 2003, 60, 413.

80. Baraldi, P. T.; Zarbin, P. H. G.; Vieira, P. C.; Corrêa, A. G.; Tetrahedron Asymmetry 2002, 13, 621; Batista-Pereira, L. G.; Stein, K.; Paula, A. F.; Moreira, J. A.; Cruz, I.; Figueiredo, M. D.; Perri, J.; Corrêa, A.G.; J. Chem. Ecol. 2006, 32, 1085; Clososki, G. C.; Ricci, L. C.; Costa, C. E.; Comasseto, J. V.; J. Braz. Chem. Soc. 2004, 15, 809; Moreira, J. A.; Corrêa, A. G.; Tetrahedron Asymmetry 2003, 14, 3787; Santangelo, E. M.; Corrêa, A. G.; Zarbin, P. H. G.; Tetrahedron Lett. 2006, 47, 5135.

81. Batista-Pereira, L. G.; Santos, M. G.; Corrêa, A. G.; Fernandes, J. B.; Dietrich, C. R. R. C.; Pereira, D. A.; Bueno, O. C.; Costa-Leonardo, A. M.; J. Braz. Chem. Soc. 2004, 15, 372; Lago, J. H. G.; Soares, M. G.; Batista-Pereira, L. G.; Silva, M. F. G. F.; Corrêa, A. G.; Fernandes, J. B.; Vieira, P. C.; Roque, N. F.; Phytochemistry 2006, 67, 589; Soares, M. G.; Batista-Pereira, L. G.; Fernandes, J. B.; Corrêa, A. G.; Silva, M. F. G. F.; Vieira, P. C.; Rodrigues Filho, E.; Ohashi, O. S.; J. Chem. Ecol. 2003, 29, 2143.

82. Araújo, C. L.; Bezerra, I. W. L.; Oliveira, A. S.; Moura, F. T.; Macedo, L. L. P.; Gomes, C. E. M.; Barbosa, A. E. A. D.; Macedo, F. P.; Souza, T. M. S.; Franco, O. L.; Bloch Júnior, C.; Sales, M. P.; J. Agric. Food Chem. 2005, 53, 4381; Garcia, V. A.; Freire, M. G. M.; Novello, J. C.; Marangoni, S.; Macedo, M. L. R.; Protein J. 2004, 23, 343.

83. Gallo, M. B. C.; Beltrame, F. L.; Vieira, P. C.; Cass, Q. B.; Fernandes, J. B.; Silva, M. F. G. F.; J. Chromatogr. B 2006, 832, 36

84. http://www.who.int/ctd/chagas/burdens.htm, acessada em Março 2007.

85. Coura, J. R.; Castro, S. L. Mem. Inst. Oswaldo Cruz 2002, 97, 3.

86. Moncayo, A.; Mem. Inst. Oswaldo Cruz 2003, 98, 577.

87. http://www.periodicos.capes.gov.br, ISI Web of Knowledge, acessada em Março 2007.

88. Souza, D. H. F.; Garrat, E. C.; Araújo, A. P. U.; Guimarães, B. G.; Jesus, W. D. P.; Michels, P. A. M.; Hannaert, V., Oliva, G.; FEBS Lett. 1998, 424, 131.

89. Vieira, P.C.; Mafezoli, J.; Pupo, M.T.; Fernandes, J.B.; Silva, M.F.G.F.; Albuquerque, S.; Oliva, G.; Pavão, F.; Pure Appl. Chem. 2001, 73, 617.

90. Pavão, F.; Castilho, M. S.; Pupo, M. T.; Dias, R. L. A.; Corrêa, A. G.; Fernandes, J. B.; Silva, M. F. G. F.; Mafezoli, J.; Vieira, P. C.; Oliva, G.; FEBS Letters 2002, 520, 13.

91. Campo, V. L.; Borges, A. D. L.; Carvalho, I.; J. Braz. Chem. Soc. 2006,
17, 648; Cardoso, C. L.; Lima, V. V.; Zotti, A.; Oliva, G.; Andricopulo, A. D.; Wainer, I. W.; Moaddel, R.; Cass, Q. B.; J. Chromatogr. A 2006, 1120, 151.

92. Silva, A. A. F.; Vieira, L. C.; Krieger, M. A.; Goldenberg, S.; Zanchin, N. I. T.; Guimarães, B. G.; J. Struct. Biol. 2007, 157, 416.

93. Gallo, M. B. C.; Marques, A. S. F.; Vieira, P. C.; Silva, M. F. G. F.; Fernandes, J. B.; Silva, M.; Guido, R. V.; Oliva, G.; Thiemann, O. H.; Albuquerque, S.; Fairlamb, A. H.; Z. Naturforsch. C: J. Biosc., submetido; Oliveira, R. B.; Vaz, A. B. M.; Alves, R. O.; Liarte, D. B.; Donnici, C. L.; Romanha, A. J.; Zani, C. L.; Mem. Inst. Oswaldo Cruz 2006, 101, 169; Rosa, L. H.; Cota, B. B.; Machado, K. M. G.; Rosa, C. A.; Zani, C. L.; World J. Microbiol. Biotechnol. 2005, 21, 983.

94. Ambrozin, A. R. P.; Mafezoli, J.; Vieira, P. C.; Fernandes, J. B.; Silva, M. F. G. F.; Ellena, J. A.; Albuquerque, S.; J. Braz. Chem. Soc. 2005, 16, 434; Ambrozin, A. R. P.; Vieira, P. C.; Fernandes, J. B.; Silva, M. F. G. F.; Albuquerque, S.; Mem. Inst. Oswaldo Cruz 2004, 99, 227; Cunha,W. R.; Crevelin, E. J.; Arantes, G. M.; Crotti, A. E. M.; Silva, M. L. A.; Furtado, N. A. J. C.; Albuquerque, S.; Ferreira, D. S.; Phytother. Res. 2006, 20, 474; Elias, B. C.; Said, S.; Albuquerque, S.; Pupo, M. T.; Microbiol. Res. 2006, 161, 273; Truiti, M. C. T.; Ferreira, I. C. P.; Zamuner, M. L. M.; Nakamura, C. V.; Sarragioto, M. H.; Souza, M. C.; Braz. J. Med. Biol. Res. 2005, 38, 1873; Zuleta, L. M. C.; Cavalheiro, A. J.; Silva, D. H. S.; Furlan, M.; Young, M. C. M.; Albuquerque, S.; Castro-Gamboa, I.; Bolzani, V. S.; Phytochemistry 2003, 64, 549.

95. Batista, R.; Humberto, J. L.; Chiari, E.; Oliveira, A. B.; Bioorg. Med. Chem. 2007, 15, 381; Faria, T. J.; Silva, L. G. F.; Souza Filho, J. D.; Chiari, E.; Oliveira, A. B.; J. Braz. Chem. Soc. 2005, 16, 1415; Vieira, H. S.; Takahashi, J. A.; Oliveira, A. B.; Chiari, E.; Boaventura, M. A. D.; J. Braz. Chem. Soc. 2002, 13, 151; Marchi, A. A.; Castilho, M. S.; Nascimento, P. G. B.; Archanjo, F. C.; Del Ponte, G.; Oliva, G.; Pupo, M. T.; Bioorg. Med. Chem. 2004, 12, 4823 .

96. Medola, J. F.; Cintra, V. P.; Silva, E. P. P.; Royo, V. A.; Silva, R.; Saraiva, J.; Albuquerque, S.; Bastos, J. K.; Silva, M. L. A.; Tavares, D. C.; Food Chem. Toxicol. 2007, 45, 638.

97. Saraiva, J.; Vega, C.; Rolon, M.; Silvam, R.; Silva, M. L. A.; Donate, P. M.; Bastos, J. K.; Gomez-Barrio, A.; Albuquerque, S.; Parasitol. Res. 2007, 100, 791.

98. Silva, M.; Silva, C. H. T. P.; Iulek, J.; Oliva, G.; Thiemann, O. H.; Biochim. Biophys. Acta 2004, 1696, 31.

99. Alves, P. B.; Freire, P. S.; Moraes, V. R. S.; Blank, A. F.; Carvalho, J. L. S.; Arrigoni-Blank, M. D.; Oliva, G.; Thiemann, O. H.; J. Essential Oil Res. 2007,19, 89; Ambrozin, A. R. P.; Leite, A. C.; Silva, M.; Vieira, P. C.; Fernandes, J. B.; Thiemann, O. H.; Silva, M. F. G. F.; Oliva, G.; Pharmazie 2005, 60, 781; Gray, C. A.; Lira, S. P.; Silva, M.; Pimenta, E. F.; Thiemann, O. H.; Oliva, G.; Hadju, E.; Andersen, R. J.; Berlinck, R. G. S.; J. Org. Chem. 2006, 71, 8685; Napolitano, H. B.; Silva, M.; Ellena, J.; Rocha, W. C.; Vieira, P. C.; Thiemann, O. H.; Oliva, G.; Acta Cryst. 2003, E59, o1503.

100. Feliciano, P. R.; Cordeiro, A. T.; Costa-Filho, A. J.; Nonato, M. C.; Protein Expression Purif. 2006, 48, 98.

101. Delorenzi, J. C.; Freire-de-Lima, L.; Gattass, C. R.; Costa, D. A.; He, L.; Kuehne, M. E.; Saraiva, B. E. M.; Antimicrob. Agents Chemother. 2002, 2111; Lima, N. M. F.; Correia, C. S.; Leon, L. L.; Machado, G. M. C.; Madeira, M. F.; Santana, A. E. G. S.; Goulart, M. O. F.; Mem. Inst. Oswaldo Cruz 2004, 99, 757; Napolitano, H. B.; Silva, M.; Ellena, J.; Rodrigues, B. D. G.; Almeida, A. L. C.; Vieira, P. C.; Oliva, G.; Thiemann, O. H.; Braz. J. Med. Biol. Res. 2004, 37, 1847; Pereira, C. G.; Rosa, P. T. V.; Meireles, M. A. A.; J. Supercrit. Fluids 2007, 40, 232; Schinor, E. C.; Salvador, M. J.; Tomaz, J. C.; Pral, E. M. F.; Alfieri, S. C.; Ito, I. Y.; Dias, D. A.; Rev. Bras. Ciências Farm. 2006, 42, 83; Stábeli, R. G.; Amui, S. F.; Sant'Ana, C. D.; Pires, M. G.; Nomizo, A.; Monteiro, M. C.; Romão, P. R. T.; Guerra-Sá, R.; Vieira, C. A.; Giglio, J. R.; Comp. Biochem. Physiol., Part C: Toxicol. Pharmacol. 2006, 142, 371.

102. Rocha, L. G.; Almeida, J. R. G. S.; Macedo, R. O.; Barbosa-Filho, J. M.; Phytomedicine 2005, 12, 514.

103. Carvalho, P. B.; Ferreira, E. I.; Fitoterapia 2001, 72, 599. 